\title{
Research on Surface Failure Law of Working Faces in Large Mining Height and Shallow Buried Coal Seam
}

\author{
Zhenhua Li, ${ }^{1}$ Yingkun Pang, ${ }^{1}$ Yongsheng Bao ${ }^{D},{ }^{2}$ and Zhanyuan $\mathrm{Ma}^{2}$ \\ ${ }^{1}$ School of Energy Science and Engineering, Henan Polytechnic University, Jiaozuo 454000, Henan, China \\ ${ }^{2}$ Datong Coal Mine Group Co. Ltd., Datong 037003, Shanxi, China \\ Correspondence should be addressed to Yongsheng Bao; yongshengbao@126.com
}

Received 21 April 2020; Revised 30 May 2020; Accepted 4 June 2020; Published 25 June 2020

Academic Editor: Hailing Kong

Copyright (c) 2020 Zhenhua Li et al. This is an open access article distributed under the Creative Commons Attribution License, which permits unrestricted use, distribution, and reproduction in any medium, provided the original work is properly cited.

In the process of high-intensity and large-space mining in Shendong mining area, various surface cracks are generated on the surface, resulting in serious damage to the surface buildings and the local ecological environment. To study the influence of overlying rock movement on surface failure of near-field single key strata of near-shallow buried and large mining height working face, the relationship between overburden movement, strata pressure appearance, and surface failure at working face 52307 in Daliuta mining area was analyzed by field measurement and numerical simulation. The results show the following: (1) there is only one thick and hard key stratum in the overburden of large mining height and near-shallow buried working face. Under the condition of presplitting roof blasting, the first weighting step is still as high as $95 \mathrm{~m}$, and the periodic breaking step of roof is 20-30 m. During the weighting, the working resistance of support is still close to the rated resistance. (2) The single key stratum plays an obvious role in controlling overburden movement. After the first weighting of the working face, a stepped subsidence crack appears on the surface within a short time, and the crack lags behind the working face for about $5 \mathrm{~m}$. (3) During each periodic weighting process, the breaking and subsidence of key blocks are accompanied by surface cracks.

\section{Introduction}

In the coal mining of working faces, the surface usually has a certain response. For example, surface soil strata can be seriously deformed, and mining cracks appear on the surface $[1,2]$. This kind of destruction is quite remarkable and poses a great threat to surface buildings, roads, and railways [3, 4]. Therefore, it is necessary to analyze and study the mechanism of surface cracks.

Many scholars have studied the development mechanism of mining-induced surface fracture. In 1981, Singh et al. [5] concluded that surface subsidence is caused by overburden fault movement. This is the beginning of a deep study on the surface and spatial-temporal evolution of overburden strata. Ghose [6], Greco [7], and Homoud [8] used fracture mechanics and plastic mechanics theory to study the mechanical mechanism of mining landslide. Luo [9] applied computer simulation technology to investigate the dynamic deformation calculation model of mining slope.
The basic laws of surface cracks have also been studied. Herrera et al. [10] and Camec and Delacourt [11] monitored land subsidence through D-InSAR and detected tensile deformation area. Hahn et al. [12] used the equipment to investigate and classify surface cracks.

With the westward movement of China's coal mining, large-space and high-intensity mining of shallow and thin bedrock coal seam has caused irreversible impact on the surface and local ecology under the special geological conditions in Northwest China $[13,14]$. A lot of research on the mechanism and development of mining-induced cracks in western mining area has been performed $[15,16]$. Liu et al. [17] analyzed the mechanism and the dynamic development law of surface cracks and surface subsidence. This study provides technical references for the placement of surface cracks. The movement of overlying strata in shallow seam mining is characterized by the full cutoff of roof strata and the large bedrock fracture angle; and the fracture directly develops to the surface, forming significant subsidence 
cracks [18]. In addition, under the condition of high-intensity mining, the surface cracks have secondary development characteristics, and there are two development cycles and corresponding two peaks $[19,20]$. At the same time, the development mechanism of surface cracks under the condition of wide and fast advance working face was analyzed in detail $[21,22]$. Hu et al. [23, 24] focused on indepth study of surface subsidence and surface cracks in aeolian sand area and proposed suggestions on the restoration of ecological environment after the destruction of aeolian sand mining. This study provides a basis for ecological restoration at that time. Sun et al. [25] put forward a "quasi-hyperbolic" settlement model on the basis of key strata theory and basic mechanics. This study provides a new theoretical basis for the study of surface subsidence and damage. Ju and Xu. [26] studied the spatial and temporal effects of different failure structures in different locations of key strata on surface damage by changing the location of key strata through similar simulation methods. Yan et al. [27], Yang et al. [28], and Zhou et al. [29] performed a lot of research on the occurrence and disaster causing of surface cracks in shallow coal seam mining and provided favorable measures for the restoration of surface ecological environment and land reclamation. Other studies on the mechanism and development characteristics of surface cracks in shallow seam mining in Western China were conducted [30-32], contributing to local ecological protection and safe mining.

However, the above studies are focused on the shallow seam mining $[33,34]$. There are few studies on the mechanism and development of surface cracks in the near-shallow seam mining (coal seam depth $>150 \mathrm{~m}$ ) [35]. Based on the geological environment of working face 52307 with shallow burial and high mining height in the Daliuta mining area, the spatial-temporal relationship between surface damage and breakage of key strata is explored in this study. In this paper, the generation and development of surface cracks under the condition of near-shallow burial is explained. This study provides a theoretical basis for the research on mininginduced cracks.

\section{Overview of Working Face}

2.1. Geological Conditions of Mining Working Face. Daliuta Coal Mine is located in Wulanmulun Town, Shenmu County, Yulin City, Shaanxi Province. With the border to Ordos city of Inner Mongolia autonomous region, this mine belongs to Shendong Coal Group. With the subordinate of Daliuta Well and Huojitu, this mine is a supersize, highyield, and high-efficiency mine in China, with an annual output of more than 20 million tons. Figure 1 shows the geographic location of the Daliuta Coal Mine.

Working face 52307 is a fully mechanized mining face with large mining height in the Daliuta mine, the ground elevation is $+1120.2-1217.1$, and the coal seam floor elevation is $+987.7-1025.5$. Most of the surface overburden strata are Quaternary loose sediments, which is $32 \mathrm{~m}$ in working face 52307, and the thickness of overlying bedrock is $158 \mathrm{~m}$. The strike length of the working face is $4462.6 \mathrm{~m}$ and the inclination length is $301 \mathrm{~m}$. The roadway layout of

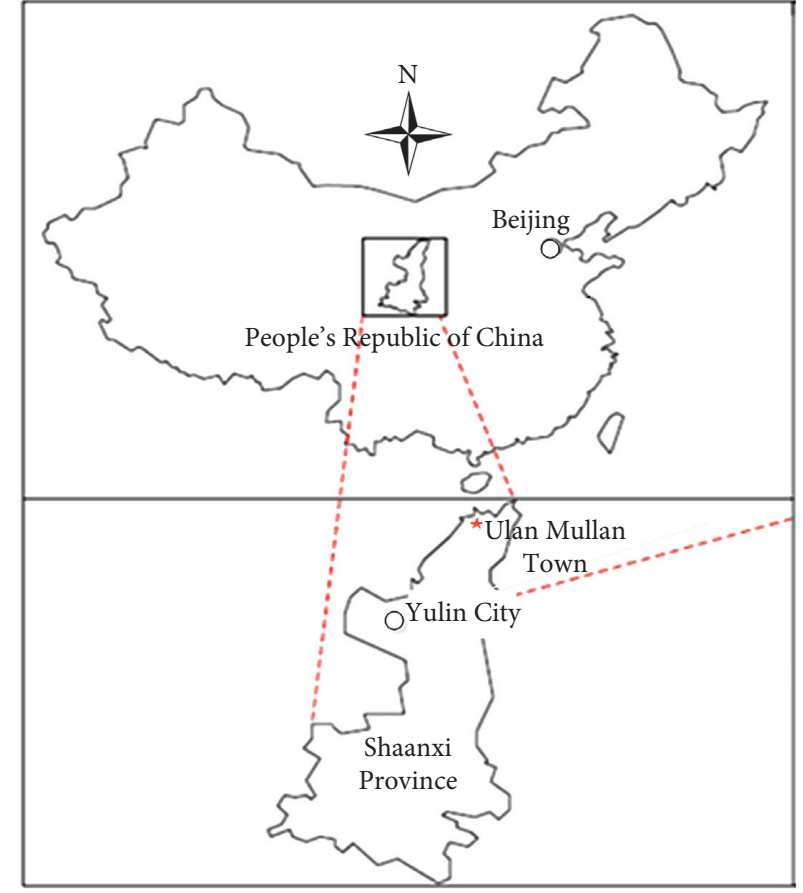

Figure 1: Geographical location of Daliuta Coal Mine.

the working face is shown in Figure 2(a). Coal 5-2 is the main working face with an average coal thickness of $7.2 \mathrm{~m}$, an average coal seam depth of $190 \mathrm{~m}$, and there is a stratum of giant fine-grained sandstone with a thickness of nearly $31 \mathrm{~m}$ at $4 \mathrm{~m}$ above the coal seam, as shown in Figure 2(b).

In the advance process of working face, various types of surface cracks appear, as shown in Figure 3. Surface cracks in Figure 3 are placed in other coal mine nearby the Daliuta mining area. Since the geological and mining conditions in coal mining area nearby the Daliuta mine are similar, the characteristics and mechanism of surface cracks caused by underground mining are the same.

2.2. Discrimination for Key Strata Location. The location of key strata is judged by two criteria of critical strata [36], namely, stiffness criterion and strength criterion. The criterion of stiffness is

$$
q_{n+1}<q_{n}
$$

where $q_{n+1}$ and $q_{n}$ are the loads on the key strata of the first strata when calculated to $n+1$ strata and $n$ strata, respectively.

To judge whether $n+1$ strata can be the key strata, the strength criterion should be satisfied, namely, the breakage distance of the lower strata should be less than that of the upper strata, shown as follows:

$$
l_{n+1}>l_{n}, \quad n=1,2, \ldots, k,
$$

where $l_{n}$ is the breakage distance of the $n$-th strata and $k$ is the determined number of hard rock strata in equation (1).

Based on the results of stiffness and strength discrimination of key strata and field settlement measurement of 


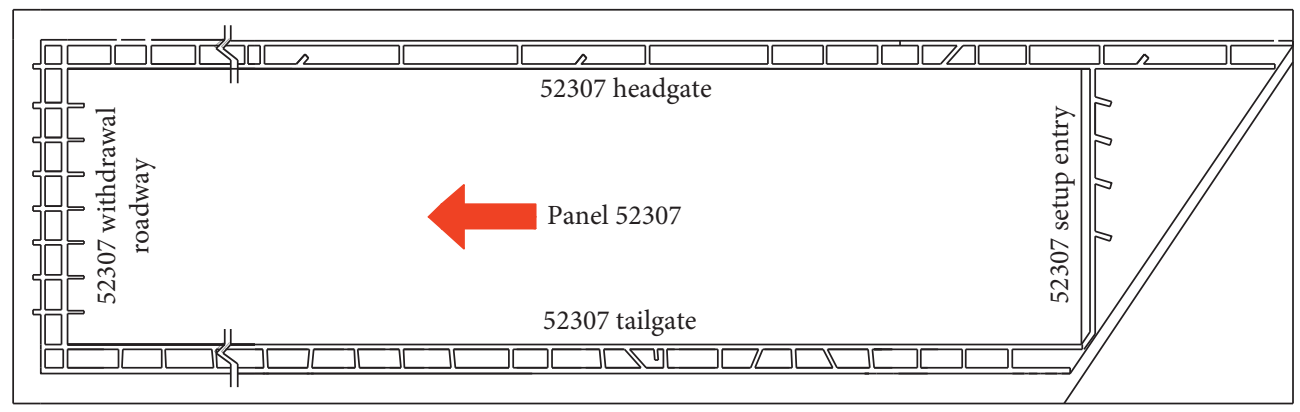

(a)

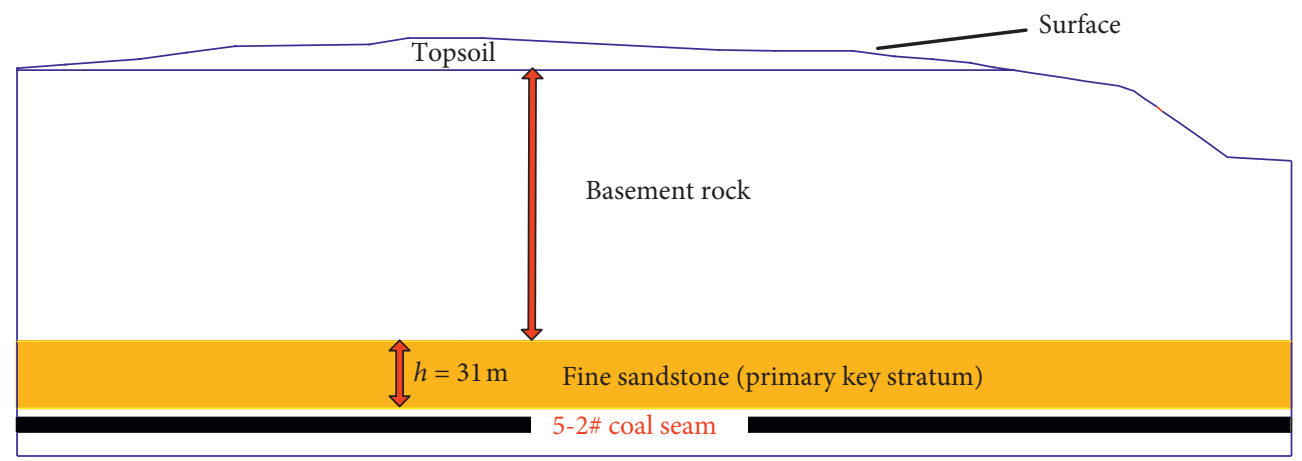

(b)

FiguRe 2: Roadway layout and overburden occurrence of working face 52307. (a) Roadway layout of working face 52307. (b) Overburden occurrence of the working face.

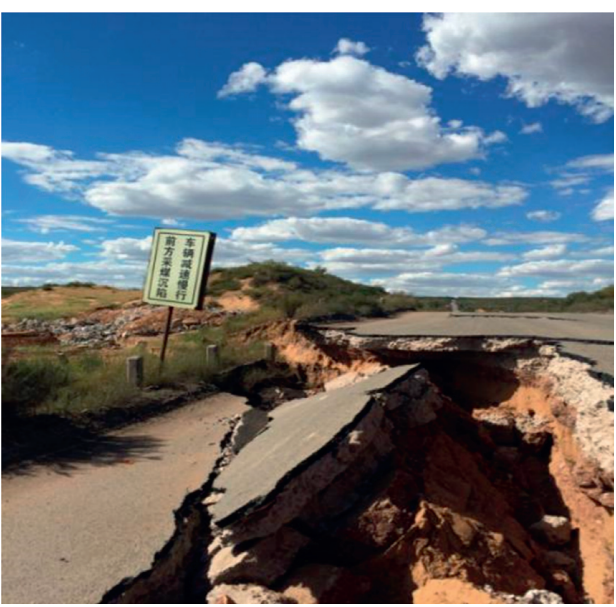

(a)

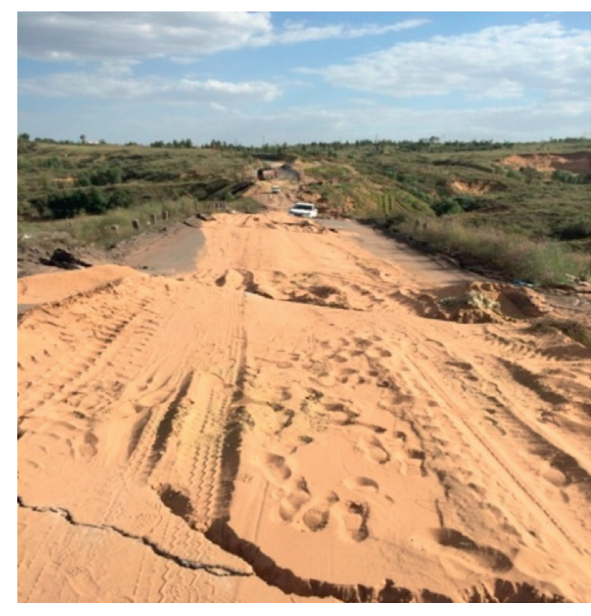

(b)

FIGURE 3: Surface cracks caused by underground mining. (a) 50 meters away from the open-off cut; (b) 120 meters away from the open-off cut.

overburden, fine-grained sandstone with a thickness of about $31 \mathrm{~m}$ in working face 52307 is determined as the main key strata in overburden strata of working face. Table 1 shows parameters of the roof and floor strata of working face.

\section{Analysis of Weighting Law of Working Face}

The mining pressure data of working face 52307 were collected by the monitored research group in the initial mining stage. Six Uloka pressure gauges are arranged at the head of the working face machine, which are located at 39\#, 40\#, 42\#, 43\#, and 44\# brackets, respectively. Eight Uloka pressure gauges are arranged at the middle of the working face, which are located at 70\#, 71\#, 72\# (the center of the working face), 73\#, 74\#, 75\#, and 76\# brackets, respectively. Five Uloka pressure gauges are arranged at the tail of the working face machine, located at 114\#, 115\#, 116\#, 117\#, and 118\# brackets. Uloka data are collected once every $1 \mathrm{~s}$. Figure 4 shows the layout of extension. 
TABLe 1: Partial table of strata parameters.

\begin{tabular}{lccc}
\hline Horizon & Lithology & Thickness $(\mathrm{m})$ & Depth $(\mathrm{m})$ \\
\hline \multirow{4}{*}{ Roof } & Fine sandstone & 31 & 175.62 \\
& Siltstone & 0.6 & 176.22 \\
& Medium sandstone & 0.7 & 176.92 \\
& Siltstone & 2.41 & 179.33 \\
\hline Coal & Coal seam 5-2\# & 7.69 & 187.02 \\
\hline \multirow{2}{*}{ Floor } & Siltstone & 3.58 & 190.60 \\
& Sandy mudstone & 2.82 & 193.42 \\
& Siltstone & 4.4 & 197.82 \\
\hline
\end{tabular}

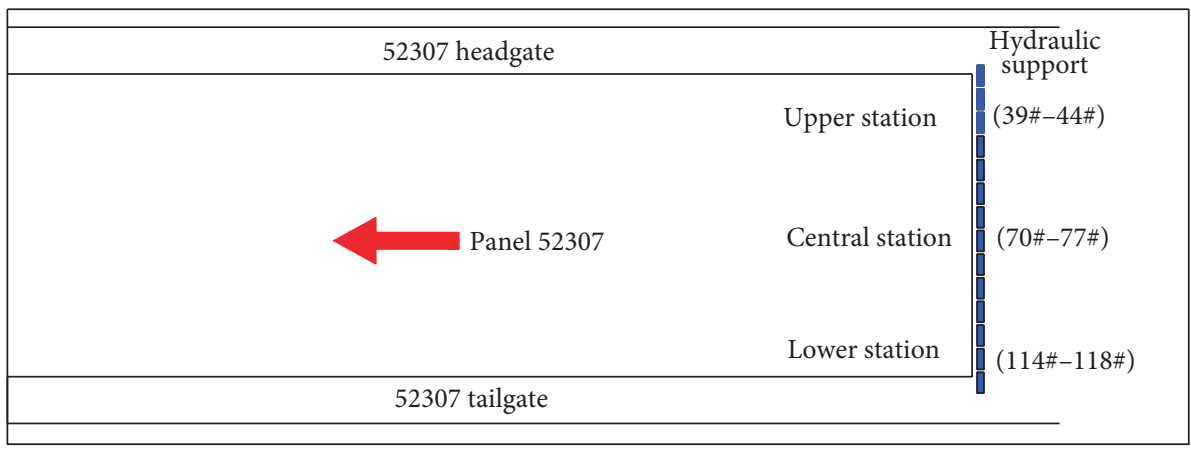

FIGURE 4: Diagram of pressure gauge distribution.

In this paper, the bracket in the middle of the working face is selected to analyze the pressure data of the bracket. Figure 5 shows the working resistance of the bracket.

The formula of weighting criterion is

$$
P_{t}^{p}=\bar{p}_{t}+\sigma_{p i}
$$

where $\bar{p}_{t}$ is the mean end-cycle resistance and $\sigma_{p i}$ is the mean square deviation.

As shown in Figure 5, when the working face advances to $955 \mathrm{~m}$, the support resistance increases rapidly, and the first weighting of the working face occurs, namely, the first weighting of the working face (when the cantilever of the main roof reaches its limit, the fracture of the main roof forms a three-hinged arch-like balance, while the broken rock blocks rotate unstably, resulting in a sharp drop of the working full roof. The load on the bracket is generally increased, and this phenomenon is called the initial weighting of the main roof). The weighting step is about $95 \mathrm{~m}$. When the working face advances to $120 \mathrm{~m}$, the second weighting occurs, namely, the first periodic weighting of the working face (the roof weighting phenomenon caused by periodic instability of rock strata in fracture zone is called periodic weighting of the working face roof), and the weighting step is $25 \mathrm{~m}$. When the working face advances to $140 \mathrm{~m}$, the second periodic weighting occurs, and the weighting step is $20 \mathrm{~m}$; within the $204 \mathrm{~m}$ range of the working face advance, there are six types of obvious periodic weighting. The largest weighting step exceeds $30 \mathrm{~m}$, averaging about $20 \mathrm{~m}$. Under the special overburden condition of single thick and hard main key strata in the near field, presplitting blasting is carried out at the cutting end of the working face, but the distance between the initial mining weighting step and throwing step can reach $95 \mathrm{~m}$, and the interval between periodic weighting step is also in the range of $20 \mathrm{~m}-30 \mathrm{~m}$.

Through detailed analysis of data, it is concluded that the average end-cycle resistance of the bracket is $17111.04 \mathrm{kN}$ during weighting and $10451.08 \mathrm{kN}$ during nonweighting.

\section{Relationship between Generation of Surface Cracks and Weighting of Working Face}

In the initial mining stage of working face 52307 in the Daliuta Mining Area, there is a stratum of fine sandstone about $31 \mathrm{~m}$ thick above the working face. Then this stratum is determined as the main key strata of the working face by the discriminant condition. The first weighting of the basic roof fracture occurs when the working face advances to $95 \mathrm{~m}$. The step subsidence of $50 \mathrm{~cm}$ is generated near the direction of $70 \mathrm{~m}$, and the subsidence of the surface measuring point is $746.7 \mathrm{~mm}$. The relationship between underground periodic pressure and surface fracture is obtained, as shown in Table 2.

The negative value in the table represents the distance between the ground fracture lagging behind the underground pressure point, while the positive value represents the distance between the ground fracture ahead of the underground pressure point. According to Table 2, when the pressure of the underground working face is applied, cracks will occur above the surface; if pressure is not applied on the working face, there are no cracks. It indicates that cracks can be generated in the working surface 52307 during nonweighting period. It further shows that the influence of overburden movement on surface deformation is intense. 


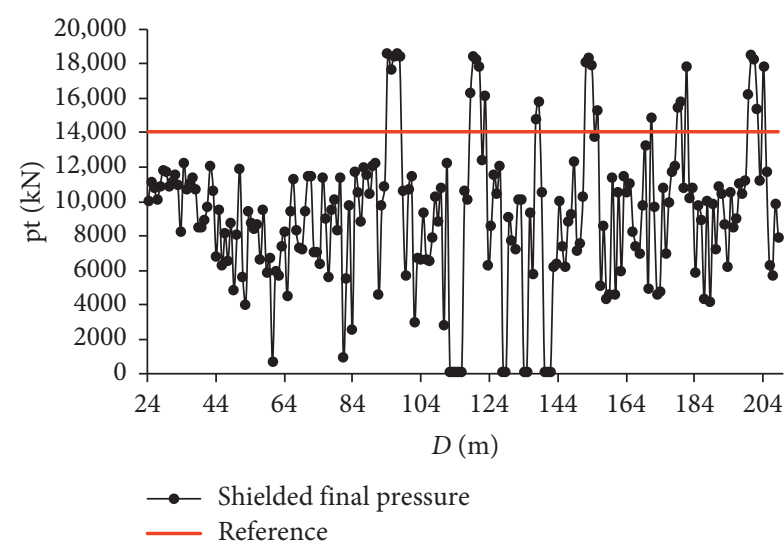

(a)

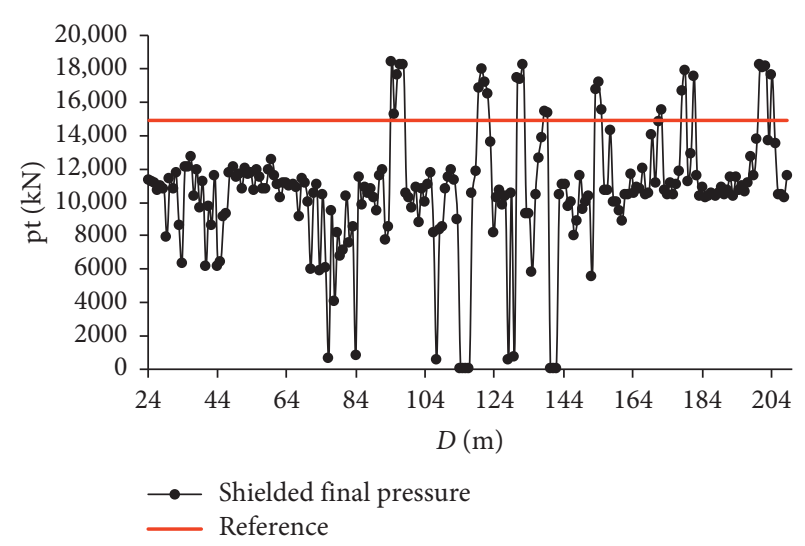

(b)

FIGURE 5: Resistance curve of the on-site monitoring bracket. (a) 71\# bracket and (b) 72\# bracket.

TABLE 2: Statistical table of periodic pressure and surface cracks.

\begin{tabular}{lccccc}
\hline Date & Advance distance $(\mathrm{m})$ & Pressure point $(\mathrm{m})$ & Pressure value $(\mathrm{kN})$ & Fracture range $(\mathrm{m})$ & Weighting distance $(\mathrm{m})$ \\
\hline 3.11 & 112.3 & 109.1 & 15837.3 & $(-23.5$ to -4.9$) 18.6$ & 2.6 \\
3.14 & 129.7 & 128.1 & 16838.3 & $(-17.7 \sim 1.3) 19$ & 19 \\
3.18 & 152.3 & 142 & 17856.3 & $(-11.8$ to -5.1$) 6.3$ & 13.9 \\
3.21 & 172.1 & 161 & 15517.9 & $(-14.3 \sim 6.2) 20.5$ & 19 \\
3.23 & 188.8 & - & - & 16 & - \\
3.24 & 195.5 & 190.4 & 17663.1 & $(-18.2$ to -7$) 11.2$ & 29.6 \\
\hline
\end{tabular}

The upper and lower wells with surface cracks are plotted, according to the periodic weighting length at the three upper and lower positions of the working face.

Three different locations in the working face are selected to arrange the hydraulic support of the Euloka station to ensure the accuracy of data collection.

The setup entry is the starting place of 52307 working face, as shown in Figure 6, during the initial weighting process of the working face, the "fixed supported beam" structure of the key bearing strata breaks in the middle, and the overburden subsides and forms a tensile force toward the middle. The overburden breaks and subsides on both sides of the corresponding surface and forms a tensile action to form the surface crack. The surface crack is shaped like a funnel in the "C" shape and the "C" direction (as shown in black box). In the latter weighting process, the periodic weighting step of the support in the middle of the working face is obviously smaller than that of the support at both ends, which results in unequal weighting step. The overburden rock in the middle of the working face has been broken, but the overburden rock at both ends has not been broken [37]. Besides, there is a "dislocation." The first fracture and subsidence of the middle roof overburden directly form a tensile force on the upper surface loess strata of this part, so that the surface cracks appear in the " $C$ " shape during the period of periodic weighting.

In the face of the periodic weighting, when the key stratum of the middle support of the working face is broken, typical cracks on the surface are compared. According to the field observation, the surface is often accompanied by various kinds of cracks during each weighting, as shown in Figure 7.

\section{Relationship between Fracture Development and Surface Subsidence}

5.1. Fracture Genesis Analysis. With the advance of the working face, uneven settlement will occur on the surface. The horizontal displacement and subsidence of the surface soil in adjacent positions are different, which will inevitably lead to the deformation of the surface overburden soil. Because of small tensile and poor shear capacity of the Quaternary loose strata [38], surface cracks occur when the tensile deformation reaches the maximum tensile deformation energy of the surface soil.

To fully study the actual deformation of the surface, an observatory is set up on the surface above the open-off cut. The horizontal section of the observatory is shown in Figure 8 .

The actual length of the observation station is $626 \mathrm{~m}$, the distance between the observation points is $20 \mathrm{~m}$, and the number of working observation points is $23 \mathrm{~m}$. By observing the surface movement and deformation of the working face and the calculation of observation data, the surface movement curve is obtained. The subsidence curve of the survey line in each observation period is shown in Figure 9.

The average depth of working face 52307 is $190 \mathrm{~m}$, and the length of working face is $301 \mathrm{~m}$; the mobile basin with stable mining will be fully exploited. During the last observation, the working face 52307 is advanced to $637.4 \mathrm{~m}$, the 


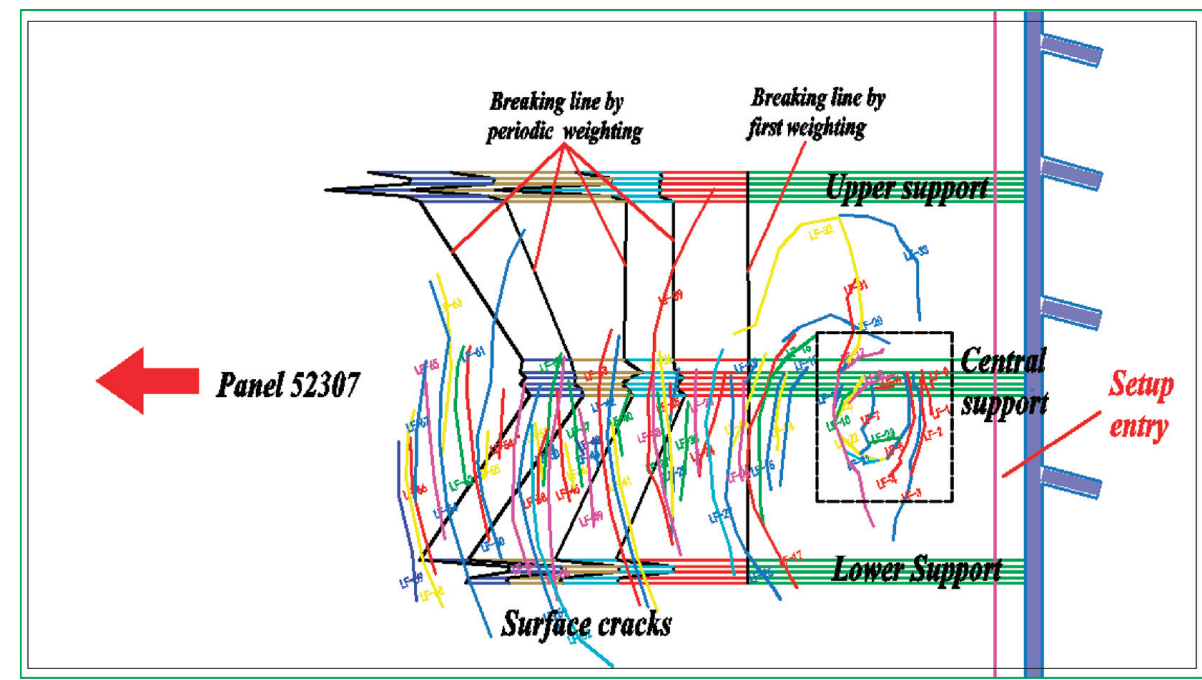

FIGURE 6: Spatial-temporal relationship between weighted breakage distance and surface cracks.

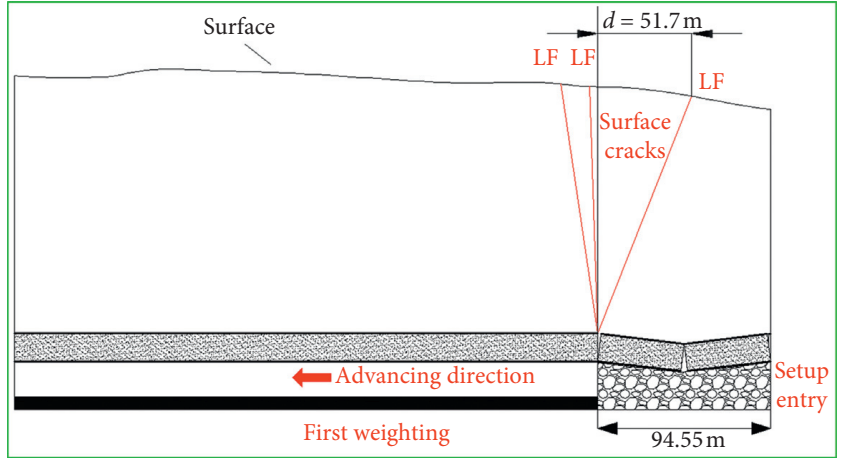

(a)

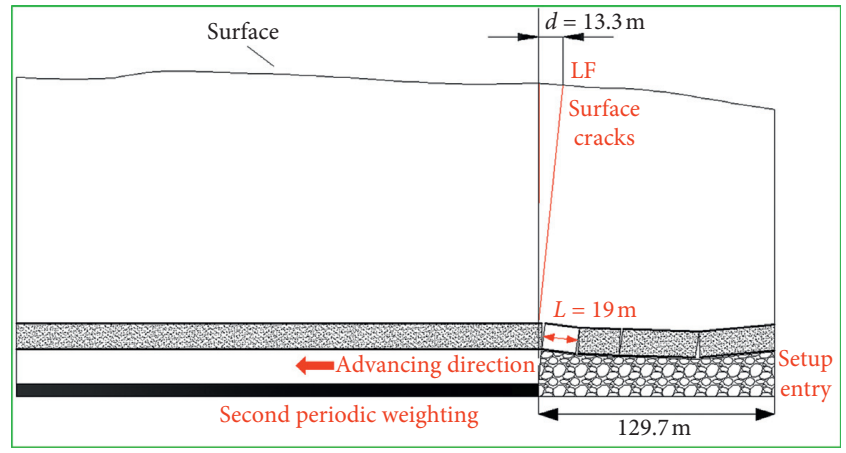

(c)

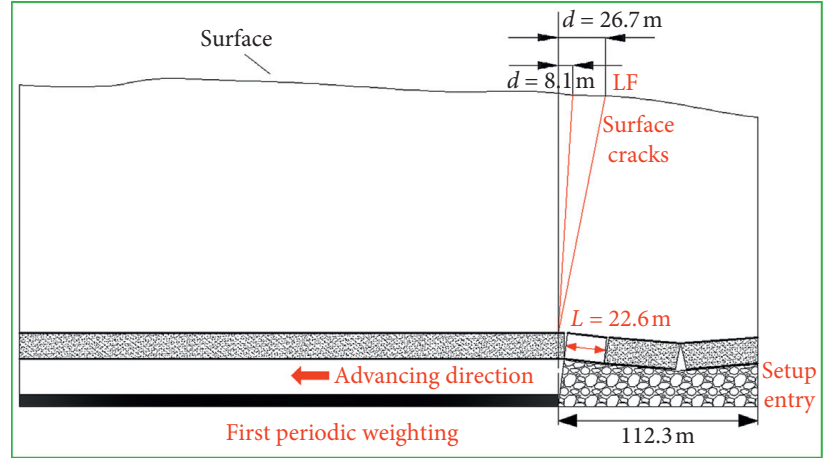

(b)

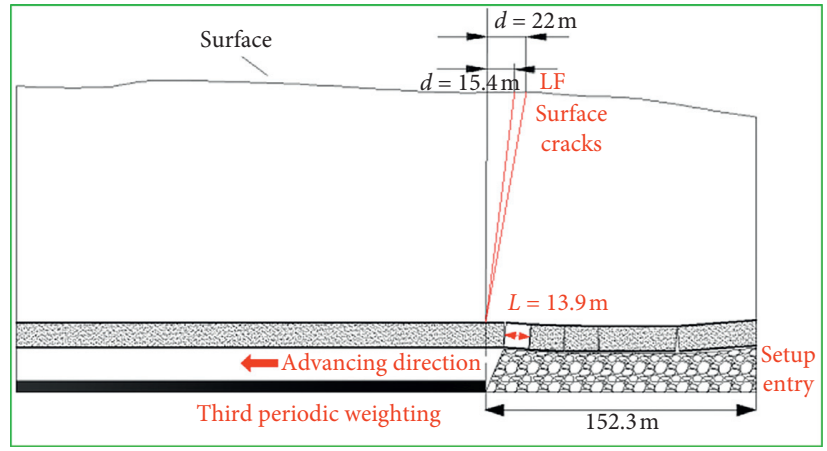

(d)

Figure 7: Contrast of broken blocks in key strata with surface-fractured wells. (a) The first weighting stage of working face, (b) the first periodic weighting stage, (c) the second periodic weighting stage, and (d) the third periodic weighting stage.

working face has reached full mining, the maximum subsidence point A22 is not changed, and the maximum value is $3560 \mathrm{~mm}$.

According to the definition of horizontal deformation, the horizontal deformation of each measurement point on the advance line can be calculated by the moving value of each measurement point in different time periods on the advance line of the working face. Then a horizontal deformation curve can be drawn, as shown in Figure 10.

From the horizontal deformation curve in the advance direction of the working face, with the mining of the working face, the horizontal deformation value of surface water increases gradually, the maximum value of tensile deformation is $46.1 \mathrm{~mm} / \mathrm{m}$, and the maximum value of compressive deformation is $-32.4 \mathrm{~mm} / \mathrm{m}$. 


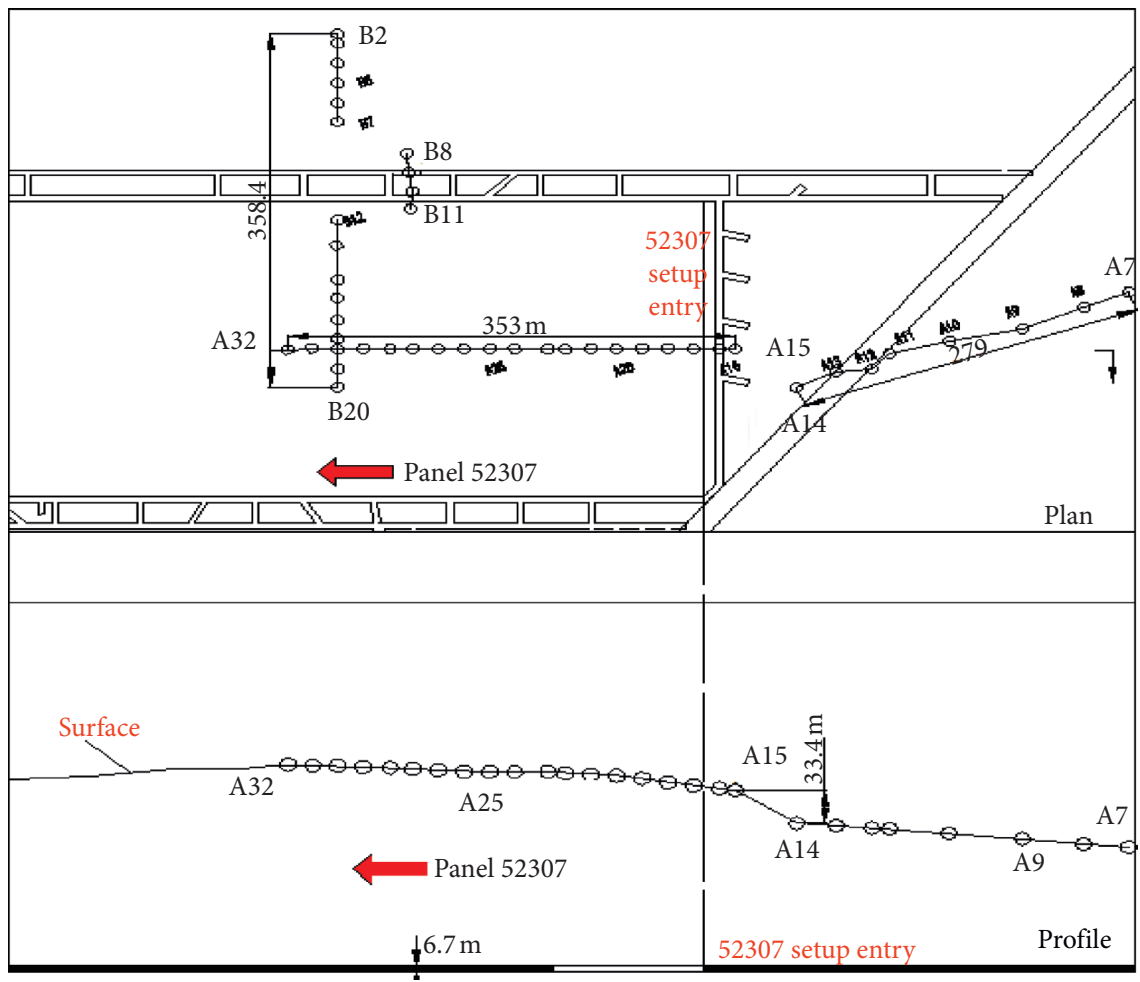

FIGURE 8: Horizontal section diagram of the observation station.

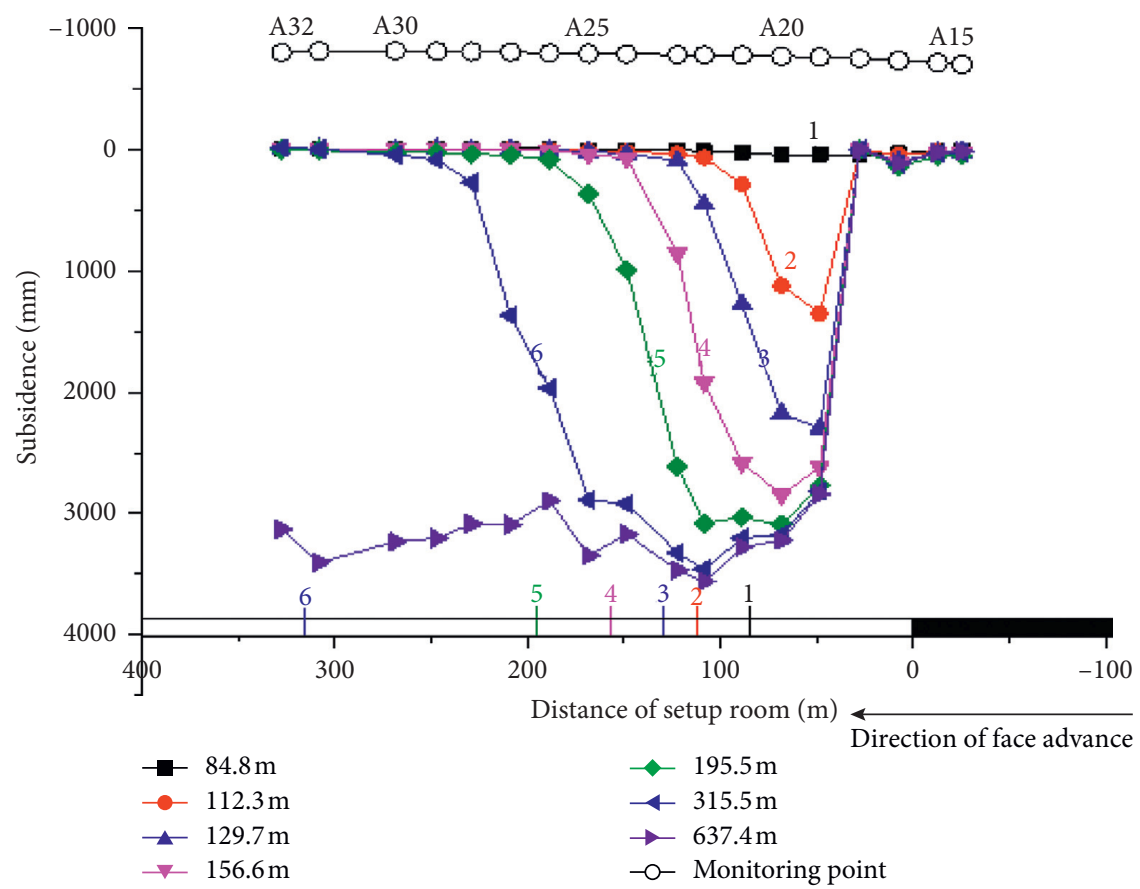

FIGURE 9: Subsidence curves.

According to Figures 9 and 10, in the advance of the working face, the surface subsides under the influence of mining, and the horizontal deformation of the surface soil changes with fluctuations. Near the measurement point A23, the maximum of surface deformation is accompanied by the maximum horizontal deformation. It indicates that the surface movement is intense, different forms of surface cracks will be formed in this area, and even multiple cracks will appear. In the actual observation, with the advance of working face, the speed of surface subsidence in the working face is fast, and the intense surface horizontal movement can be observed. The movement of the overburden subsidence 


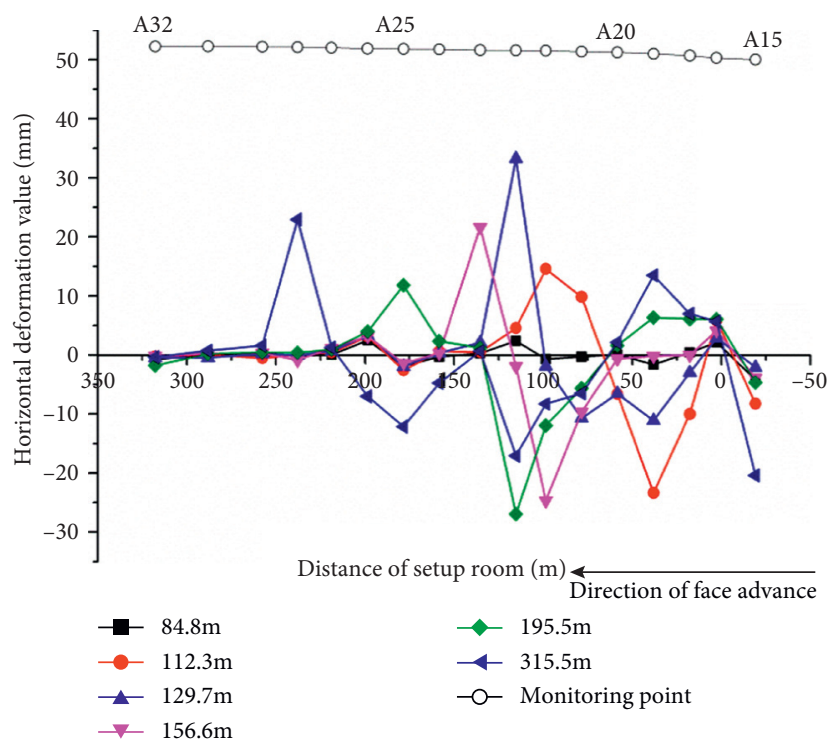

FIgURE 10: Horizontal deformation curves.

results in a sharp subsidence of the topsoil strata. However, there exists the uneven subsidence because the subsidence speed between adjacent soils is not uniform in time. At this moment, the soil bears great tensile stress. When the tensile force is greater than the limit bearing force of the soil, dislocation is caused between the adjacent soils in the vertical direction, and surface cracks are generated.

\subsection{Field Measurement of Surface Crack Morphology.}

Surface cracks in the stations are recorded, and the characteristics of ground deformation and cracks are studied. The crack situation is shown in Figure 11. With the advance of the working face, surface cracks are generated.

The distribution of cracks in the middle of the surface is basically parallel to the working face, some of which bend towards the goaf, and the overall shape of the cracks presents a " $C$ " shape. At the beginning of mining in the working face, the surface dynamic cracks are mainly distributed in the middle of the working face. When the working face advances to about $450 \mathrm{~m}$, fewer permanent cracks are found above the open-off cut, along the grooves on both sides of the working face and the adjacent areas. Meanwhile, surface subsidence is serious in the process of on-site investigation and mining, and there will be different forms of surface cracks in the field, as shown in Figure 12. Surface cracks caused by underground mining can be classified as tensile cracks, hysteretic extrusion crack, and stepped cracks. Tensile cracks are caused by tensile stress, hysteretic extrusion cracks are caused by compressive stress, and stepped cracks are caused by shearing stress in Quaternary loose sediments.

Through the analysis of the surface tensile cracks and the advance of the underground working face, it is known that the position of the cracks always lags behind the mining position of the working face for a certain distance. Stepped cracks are formed by mining-induced overburden breakage and surface subsidence, generally lagging behind the working face. Their mechanism can be divided into basic roof breaking principle based on thin plate theory and key strata theory. Based on the analysis of stepped cracks in working face 52307 of Daliuta, it is considered that the occurrence of stepped cracks is closely related to the lag distance of cracks, subsidence value, and horizontal deformation value of surface points of cracks. These cracks are located in the tensile deformation area, rather than the extrusion area, and their deformation value and subsidence value are relatively large.

Traditionally, it is generally believed that dynamic cracks open first and then close gradually with the advance of the working face. The width of cracks generally presents a single peak period and increases from small to large and finally tends to close. Based on the statistics of all cracks in working face 52307, the development time of tensile, extrusion, and stepped cracks are analyzed, respectively. Tensile crack, which is located behind the working face in Daliuta, generally undergoes the process of "opening-large-closing." It has a small deformation value and short duration (averaging 4.8 days). The maximum distance pushed by the working face is $40 \mathrm{~m}$, the minimum is $17.4 \mathrm{~m}$, and the average is $24.8 \mathrm{~m}$. In the advance process of the working face, some cracks do not close after opening but only undergo the process of "opening-large-unchanged." These cracks are generally located near the open-off cut of the working face, with an average duration of 7.6 days. The maximum distance pushed by the working face is $48.9 \mathrm{~m}$, the minimum is $33.3 \mathrm{~m}$, and the average is $41.5 \mathrm{~m}$. Stepped cracks are destructive cracks. They have small change range and rarely change after the generation, undergoing the process of "opening-unchanged." These cracks generally lie behind the working face and last for an average of 5.2 days. The maximum distance pushed by the working face is $27.8 \mathrm{~m}$, the minimum is $19.7 \mathrm{~m}$, and the average is $24.3 \mathrm{~m}$. The extrusion crack is the same as the stepped 


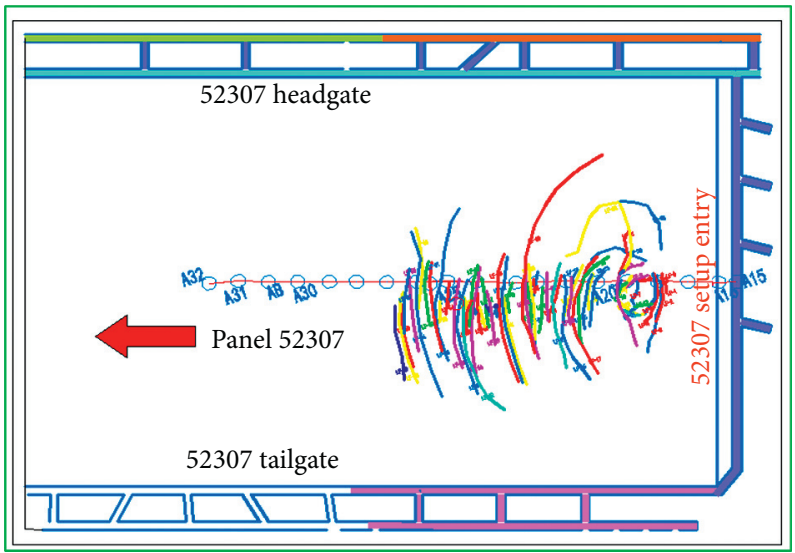

FIGURE 11: Contrast map for surface cracks in working face 52307 and observation station.

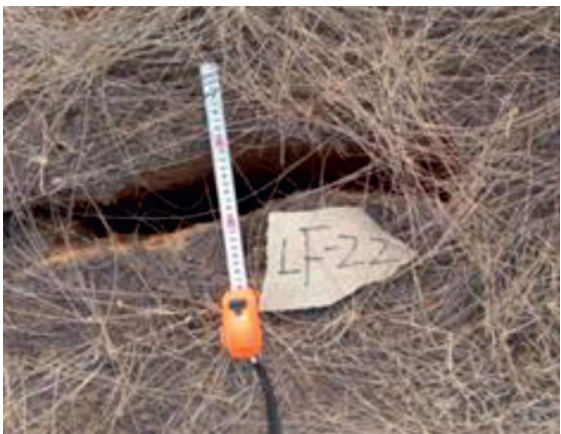

(a)

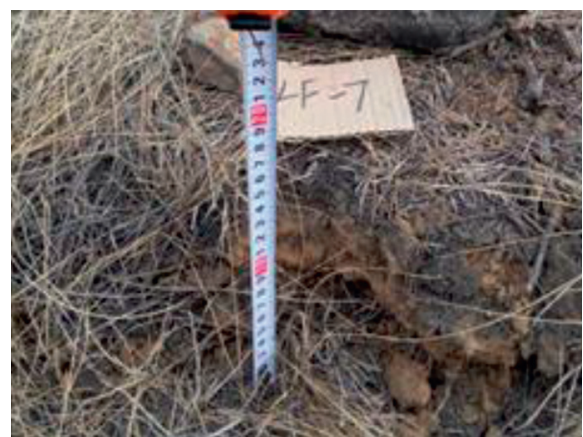

(b)

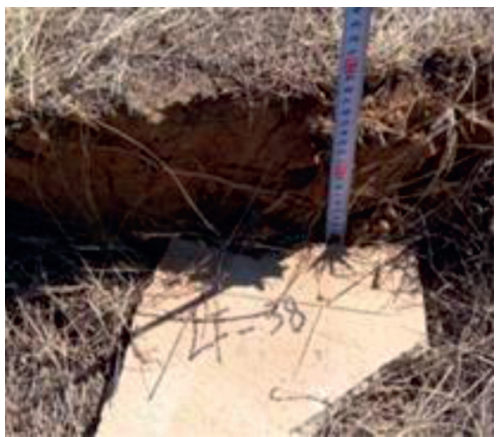

(c)

FIGURE 12: Classification of surface cracks in the working face. (a) Tensile cracks, (b) hysteretic extrusion crack, and (c) stepped cracks.

crack, but the damage degree of extrusion crack is far less than the stepped crack. They have small change range and rarely change after the generation, undergoing the process of "opening-unchanged." These cracks generally lie behind the working face and last for an average of 5.3 days. The maximum distance pushed by the working face is $33.3 \mathrm{~m}$, the minimum is $21.8 \mathrm{~m}$, and the average is $29.5 \mathrm{~m}$.

\section{Verification and Analysis of Numerical Simulation of Working Face}

6.1. Model Design. CDEM software is the abbreviation for Continuum-Based Discrete Element Method, which is the coupling of continuous medium algorithm (such as finite element) and discontinuous medium algorithm (such as discrete element), developed by Institute of Mechanics, Chinese Academy of Sciences. By controlling the block (finite element calculation in the block, discrete element calculation in the boundary), to simulate the deformation and movement characteristics of materials in discontinuous and continuous states, the failure process of materials can be realized. The numerical model of the hydraulic support is embedded in the simulation. According to the data of drilling strata in the initial mining stage of the working face, the model has 45 strata and the strike length is $600 \mathrm{~m}$; Table 3 shows rock mechanics parameters in numerical simulation. In numerical simulation, the upper boundary is free face, and the bottom boundary is the vertical displacement restriction; the right and left boundary are both the horizontal displacement restriction. The constitutive model of hydraulic support adopts the numerical constitutive model which characterizes the relationship between the support shrinkage and the working resistance of the support. According to the calculation principle and characteristics of the software, to eliminate the influence of boundary effect, $100 \mathrm{~m}$ boundary pillars are left on both sides, the actual mining length is $400 \mathrm{~m}$, and the simulated working face advances $400 \mathrm{~m}$ along the openoff cut. The establishment of surface morphology is based on the field data such as the contrast map, the layout map of surface survey lines, as shown in Figure 13. There are 9065 block units in the model. According to the different lithology and thickness of each stratum, the block size of each stratum is different, and the characteristics of overburden breakage in situ can be restored to the greatest extent. And the plane numerical model is suitable for reflecting the relationship between underground mining and surface cracks. 
TABLE 3: Rock mechanics parameters in numerical simulation.

\begin{tabular}{|c|c|c|c|c|c|}
\hline No. & Lithology & Thickness (m) & Tensile strength $(\mathrm{GPa} / \mathrm{MPa})$ & Modulus of elasticity (MPa/GPa) & Density $\left(\mathrm{kg} \cdot \mathrm{m}^{-3}\right)$ \\
\hline 45 & Loess strata & 11 & - & - & 1643 \\
\hline 44 & Sandy mudstone & 5 & 1.59 & 1.34 & 2280 \\
\hline 43 & Siltstone & 2 & 2.97 & 2.16 & 2312 \\
\hline 42 & Sandy mudstone & 3 & 3.09 & 2.63 & 2287 \\
\hline 41 & Siltstone & 1 & 2.86 & 1.92 & 2309 \\
\hline 40 & Sandy mudstone & 2 & 2.41 & 4.19 & 2325 \\
\hline 39 & Mudstone & 4 & 2.52 & 4.2 & 2323 \\
\hline 38 & Siltstone & 2 & 2.56 & 4.51 & 2282 \\
\hline 37 & Sandy mudstone & 6 & 2.58 & 4.83 & 2345 \\
\hline 36 & Coarse-grained sandstone & 14 & 1.08 & 2.08 & 1997 \\
\hline 35 & Medium-grained sandstone & 4 & 1.65 & 2.95 & 2111 \\
\hline 34 & Sandy mudstone & 3 & 3.95 & 7.72 & 2318 \\
\hline 33 & Coarse-grained sandstone & 2 & 4.68 & 5.68 & 2372 \\
\hline 32 & Sandy mudstone & 5 & 5.37 & 7.72 & 2352 \\
\hline 31 & Fine-grained sandstone & 2 & 2.75 & 35 & 2593 \\
\hline 30 & Siltstone & 8 & 3.73 & 6.92 & 2367 \\
\hline 29 & Sandy mudstone & 3 & 4.4 & 5.53 & 2405 \\
\hline 28 & Sandy mudstone & 2 & 5.66 & 6.15 & 2363 \\
\hline 27 & Siltstone & 3 & 3.73 & 6.92 & 2367 \\
\hline 26 & Sandy mudstone & 3 & 6.54 & 12.4 & 2606 \\
\hline 25 & Fine-grained sandstone & 3 & 5.35 & 10 & 2343 \\
\hline 24 & Sandy mudstone & 3 & 6.54 & 12.4 & 2606 \\
\hline 23 & Siltstone & 2 & 3.73 & 6.92 & 2367 \\
\hline 22 & Argillaceous sandstone & 7 & 5.75 & 7.5 & 2366 \\
\hline 21 & Fine-grained sandstone & 2 & 3.56 & 4.19 & 2263 \\
\hline 20 & Mudstone & 4 & 5.2 & 8.21 & 2374 \\
\hline 19 & Fine-grained sandstone & 4 & 5.71 & 16.3 & 2295 \\
\hline 18 & Fine-grained sandstone & 3 & 6.01 & 15.6 & 2406 \\
\hline 17 & Sandy mudstone & 2 & 6.79 & 6.8 & 2425 \\
\hline 16 & Siltstone & 2 & 6.27 & 11.7 & 2403 \\
\hline 15 & Sandy mudstone & 4 & 5.47 & 6.08 & 2446 \\
\hline 14 & Siltstone & 6 & 8.08 & 15.7 & 2494 \\
\hline 13 & Medium-grained sandstone & 5 & 5.62 & 9.78 & 2256 \\
\hline 12 & Siltstone & 1 & 7.21 & 9.3 & 2387 \\
\hline 11 & Sandy mudstone & 4 & 5.6 & 7.7 & 2482 \\
\hline 10 & Fine-grained sandstone & 31 & 4.93 & 14.1 & 2360 \\
\hline 9 & Siltstone & 4 & 9.26 & 14 & 2430 \\
\hline 8 & Coal 5-2 & 7 & 1.08 & 2.08 & 1290 \\
\hline 7 & Siltstone & 4 & 7.84 & 12.9 & 2512 \\
\hline 6 & Sandy mudstone & 3 & 8.58 & 11 & 2482 \\
\hline 5 & Siltstone & 4 & 7.22 & 18.5 & 2546 \\
\hline
\end{tabular}

Groups 1, 2, 3, and 4 are the groups of scaffolds in the simulation.

\subsection{Simulation Process and Result Analysis}

6.2.1. Simulation Process. The working face starts from the open-off cut and excavates $5 \mathrm{~m}$ each time. Then the advance of $5 \mathrm{~m}$ in the working face is simulated. As a result, the mining of working face can be stimulated in a rapid a process.

Because the main key stratum belongs to the near-field key strata, according to the theoretical formula, the stratified breakage supplementary caving zone is generated at the thickness of $16 \mathrm{~m}$, and the remaining $15 \mathrm{~m}$ is the basic top of the key strata, that is, the key bearing strata of the whole overburden. When the working face advances $95 \mathrm{~m}$, the "fixed beam" on the basic top of the key strata breaks the first weighting of the working face, and then surface cracks occur, as shown in Figure 14.
Due to the existence of tensile force, there are two obvious surface cracks on both sides above the open-off cut, the support and the coal wall, respectively. The cracks above the open-off cut are permanent cracks, which will not close with the advance of working face; the width of the cracks above the working face and the coal wall is between $0.5 \mathrm{~m}$ and $1 \mathrm{~m}$. The penetration depth of the crack is about $5 \mathrm{~m}$, and the crack hysteresis working face is $10 \mathrm{~m}$.

The first periodic weighting occurs when the working face advances to $115 \mathrm{~m}$. The tensile cracks formed in the upper stage are closed due to the extrusion force behind them, while the breaking and subsidence of the key bearing blocks lead to the generation of new surface cracks.

According to Figure 15(a), two surface cracks are formed in this stage, both of which are hysteretic surface cracks. The first crack lags the working face within the 


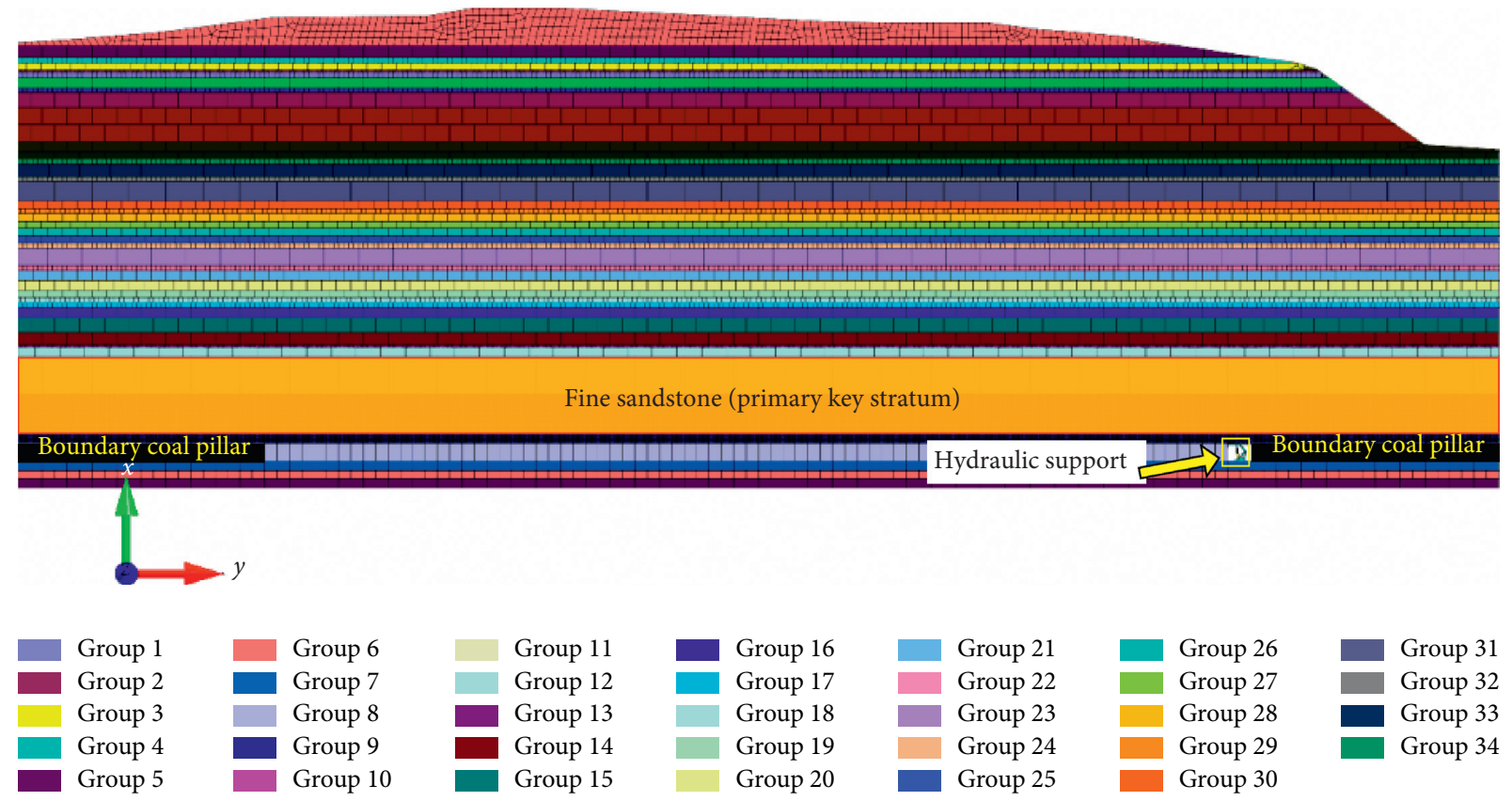

Figure 13: Numerical simulation.

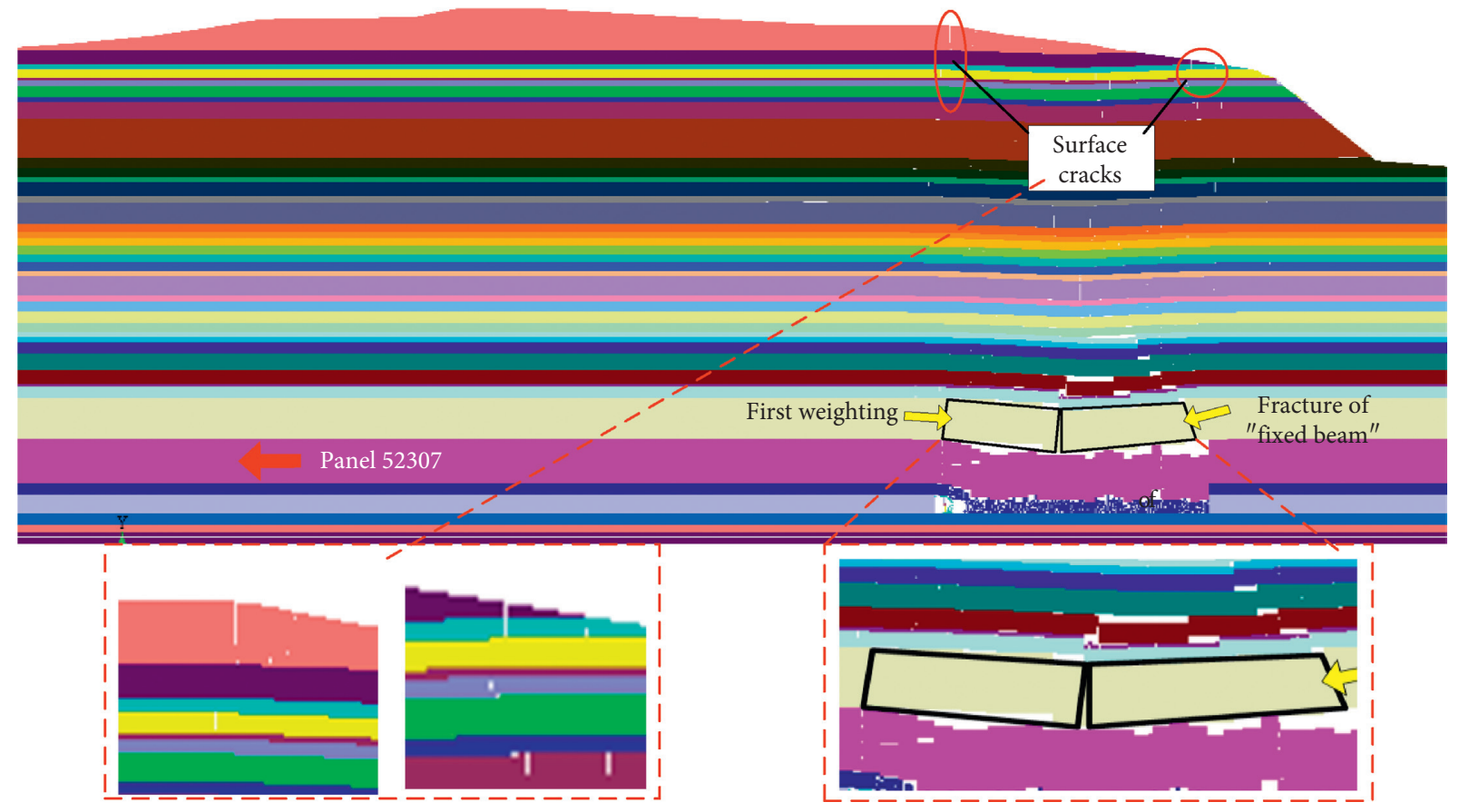

FIGURE 14: Initial weighting of working face.

range of 6-9 $\mathrm{m}$, the second surface crack lags the working face is about $25 \mathrm{~m}$. Due to the different distance from the side of goaf, the farther the distance, the greater the tension effect. Thus, the penetration depth of the first crack is greater than that of the second one. There is little difference in the lag distance of cracks at this stage in the simulation and in the field. The second periodic weighting occurs when the working face advances $130 \mathrm{~m}$, as shown in Figure 15(b).
The key blocks of the key bearing strata break down and subside, and the surface cracks are very obvious. The crack lags behind the working face between $12 \mathrm{~m}$ and $15 \mathrm{~m}$, and the width of the crack opening is about $1 \mathrm{~m}$, which is larger than that of the first periodic weighting and deeper penetration into the bedrock.

Because there is only one key strata structure in the working face, and it belongs to the near-field key strata, 


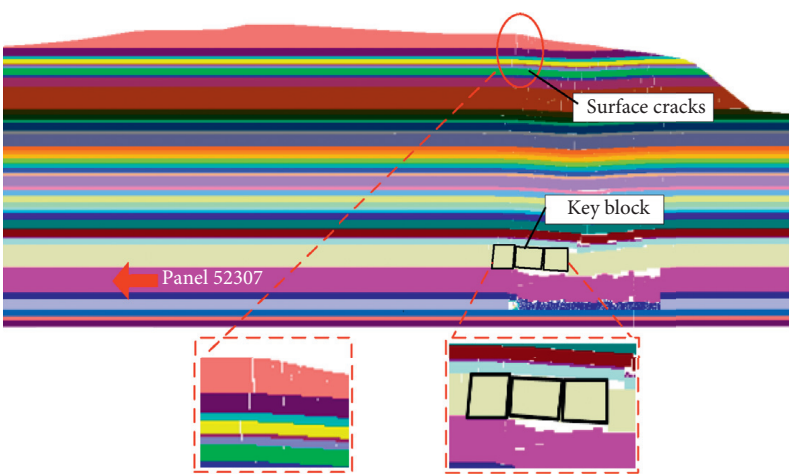

(a)

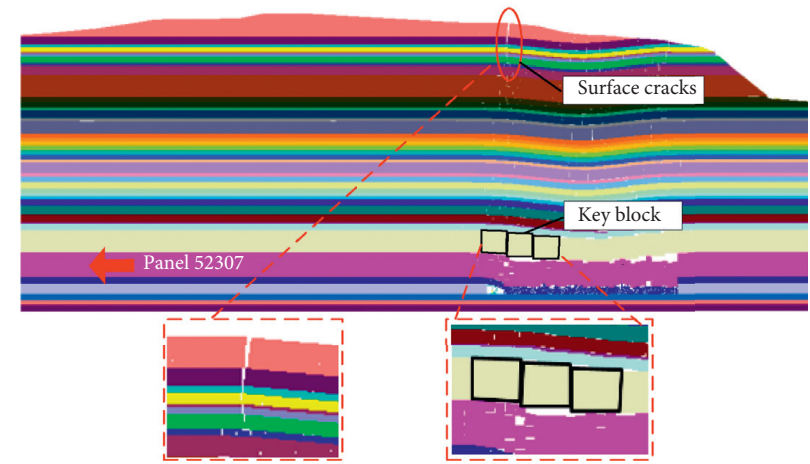

(b)

FIgURE 15: Periodic weighting of working face. (a) First periodic weighting. (b) Second periodic weighting.

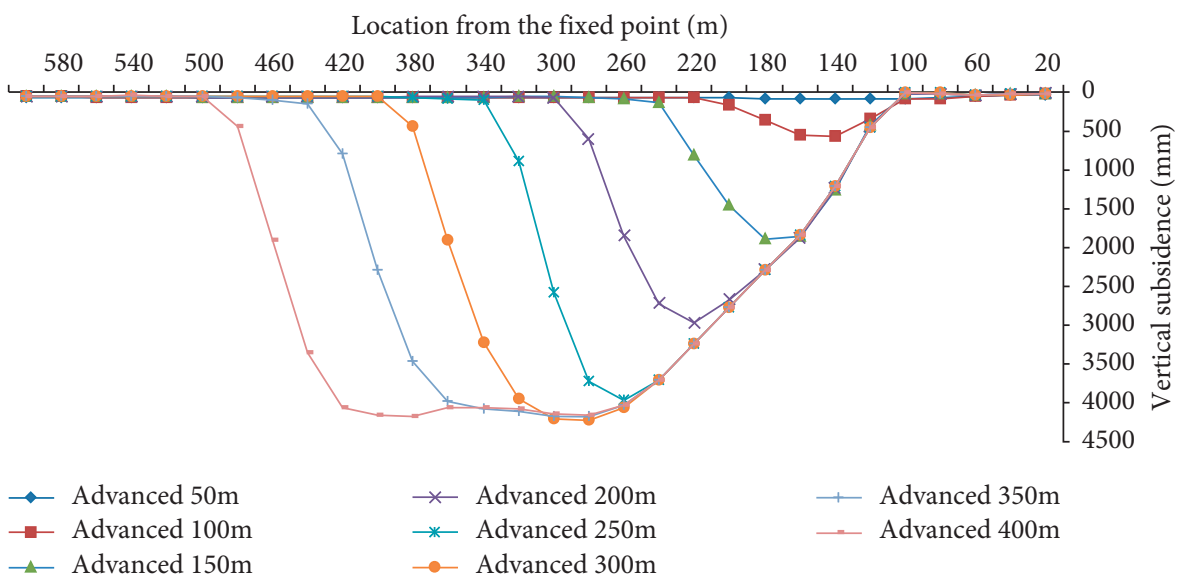

Figure 16: Surface subsidence curve.

when the key block of the key bearing strata breaks and has the subsidence displacement, the overburden bedrock will show the breakage and the subsidence displacement simultaneously. As a result, the surface also shows subsidence displacement, and the working face the first weighting. Within the initial weighting range of the working face, the key strata basic top break first subsides displacement, the overlying strata above follow, and the surface also has a certain subsidence at this time.

In the numerical simulation, the measured points are arranged along the surface of the model, and the surface subsidence at each step of excavation is monitored in real time. Figure 16 shows the surface subsidence curve.

As shown in Figure 16, when the initial weighting range of the working face is pushed to $100 \mathrm{~m}$, the surface has already subsided. When the working face advances to 100 , the maximum subsidence of surface survey points is $571 \mathrm{~mm}$. When the working face advances $400 \mathrm{~m}$, that is, when the excavation of the model is completed, the final subsidence of the surface survey line is $4,175 \mathrm{~mm}$, and the surface subsidence value is $3,560 \mathrm{~mm}$ in the field measurement. Although there are some errors in the field measurement, the errors are unavoidable due to the difference between the numerical simulation and the rock strata change in the field.

\section{Conclusions}

(1) By distinguishing the overburden lithology and key strata of working face 52307 with shallow burial and high mining height in the Daliuta mining area, it is concluded that fine-grained sandstone with a thickness of $31 \mathrm{~m}$ or so above the coal seam is the main key strata of the overburden of the working face. According to the analysis of support pressure data of working face, after a roof prefracturing project, the first weighting step of working face still reaches about $95 \mathrm{~m}$, and the periodic weighting step is in the range of $30 \mathrm{~m}-20 \mathrm{~m}$, which indicates that the weighting step of working face is larger.

(2) Through the analysis of statistical results of the observation stations on the surface above the working face, after fully mining, the surface survey lines are observed; the maximum subsidence of the surface is $3560 \mathrm{~mm}$ from the last observation, because the key strata can control the whole overburden movement from the key strata to the surface. At the same time, the horizontal deformation curve also shows that the surface deformation is serious along with the advance of the working face. According to the statistics of the cracks, with the 
breaking movement of the overburden, various types of surface cracks appear on the surface, mainly tensile ground cracks, which lag behind the working face.

(3) Through the validation of numerical simulation, with the advance of the working face, the key bearing strata breaks and subsides, and the overburden bedrock moves as a whole, resulting in obvious lagging surface cracks.

\section{Data Availability}

The data used to support the findings of this study are included within the article.

\section{Conflicts of Interest}

The authors declare that they have no conflicts of interest.

\section{Acknowledgments}

This work was supported by the National Natural Science Foundation of China (51774110, 51704095, and U1904128) and Program for Science \& Technology Innovation Talents in Universities of Henan Province (19HASTIT047).

\section{References}

[1] E. H. Bai, W. B. Guo, Y. Tan, and D. M. Yang, "Special features and mechanism of the surface response to the high-intensity mining in the thick seam mining activities," Journal of Safety and Environment, vol. 18, no. 2, pp. 503-508, 2018.

[2] J. R. Kang, "Analysis of the effect of fissures caused by underground mining on ground movement and deformation," Chinese Journal of Rock Mechanics and Engineering, vol. 27, no. 1, pp. 59-64, 2008.

[3] D. Ma, J. Wang, X. Cai et al., "Effects of height/diameter ratio on failure and damage properties of granite under coupled bending and splitting deformation," Engineering Fracture Mechanics, vol. 220, p. 106640, 2019.

[4] Q. F. Hu, X. M. Cui, D. B. Yuan, and X. B. Deng, "Formation mechanism of surface cracks caused by thick seam mining and hazard analysis," Journal of Mining and Safety Engineering, vol. 29, no. 6, pp. 864-869, 2012.

[5] M. Singh and M. F. Dunn, "Investigation of problems and benefits of underground multiple seam coal mining," Final Technical Report, US Department of Energy, Washington, DC, USA, 1981.

[6] A. K. Ghose, "Green mining-unifying concept for mining industry," Journal of Mines, Metals \& Fuels, vol. 52, no. 12, pp. 393-395, 2004.

[7] V. R. Greco, "Efficient Monte Carlo technique for locating critical slip surface," Journal of Geotechnical Engineering, vol. 122, no. 7, pp. 517-525, 1996.

[8] A. I. Homoud, Studying Theory of Displacement and Deformation in the Mountain Areas under the Influence of Underground Exploitation, AGH University of Science and Technology, Kraków, Poland, 1999.

[9] Y. Luo and S. S. Peng, "Integrated approach for predicting mining subsidence in hilly terrain," Mining Engineering, vol. 51, no. 6, pp. 100-104, 1999.
[10] G. Herrera, M. I. Álvarez Fernández, R. Tomás et al., "Forensic analysis of buildings affected by mining subsidence based on Differential Interferometry (Part III)," Engineering Failure Analysis, vol. 24, pp. 67-76, 2012.

[11] C. Tomás and C. Delacourt, "Three years of mining subsidence monitored by SAR interferometry, near Gardanne, France," Journal of Applied Geophysics, vol. 43, no. 1, pp. 43-54, 2000.

[12] C. J. Hahn, S. W. Kim, and H. S. Jung, "Satellite observation of coal mining subsidence by persistent scatter analysis," Engineering Geology, vol. 92, pp. 1-13, 2007.

[13] D. Ma, H. Duan, W. Liu, X. Ma, and M. Tao, "Water-sediment two-phase flow inrush hazard in rock fractures of overburden strata during coal mining," Mine Water and the Environment, vol. 39, no. 2, pp. 308-319, 2020.

[14] Y. Xue, T. Teng, F. Dang, Z. Ma, S. Wang, and H. Xue, "Productivity analysis of fractured wells in reservoir of hydrogen and carbon based on dual-porosity medium model," International Journal of Hydrogen Energy, pp. 1-10, 2019.

[15] W.-l. Shen, J.-b. Bai, W.-f. Li, and X.-y. Wang, "Prediction of relative displacement for entry roof with weak plane under the effect of mining abutment stress," Tunnelling and Underground Space Technology, vol. 71, pp. 309-317, 2018.

[16] Z. Z. Cao, P. Xu, Z. H. Li, M. X. Zhang, Y. Zhao, and W. L. Shen, "Joint bearing mechanism of coal pillar and backfilling body in roadway backfilling mining technology," CMC-computers Materials \& Continua, vol. 54, no. 2, pp. 137-159, 2018.

[17] H. Liu, C. G. He, K. Z. Deng, S. G. Lei, and A. B. Zhang, "Analysis of forming mechanism of collapsing ground fissure caused by mining," Journal of Mining and Safety Engineering, vol. 30, no. 3, pp. 380-384, 2013.

[18] Q. X. Huang, "Roof structure theory and support resistance determination of longwall face in shallow seam," International Journal of Coal Science \& Technology, no. 2, pp. 21-24, 2003.

[19] D. W. Zhou, K. Wu, Z. H. Bai et al., "Formation and development mechanism of ground crack caused by coal mining: effects of overlying key strata," Bulletin of Engineering Geology and the Environment, vol. 78, no. 2, pp. 1025-1044, 2017.

[20] L. Li, K. Wu, Z. Q. Hu, Y. K. Xu, and D. W. Zhou, “Analysis of developmental features and causes of the ground cracks induced by oversized working face mining in an aeolian sand area," Environmental Earth Sciences, vol. 76, no. 3, p. 135, 2017.

[21] Y. Xu, K. Wu, L. Li, D. Zhou, and Z. Hu, "Ground cracks development and characteristics of strata movement under fast excavation: a case study at Bulianta coal mine, China," Bulletin of Engineering Geology and the Environment, vol. 78, no. 1, pp. 325-340, 2019.

[22] Y. Xue, P. G. Ranjith, F. Dang et al., "Analysis of deformation, permeability and energy evolution characteristics of coal mass around borehole after excavation," Natural Resources Research, pp. 1-19, 2020.

[23] Z. Hu, C. Chen, W. Xiao, X. Wang, and M. Gao, "Surface movement and deformation characteristics due to high-intensive coal mining in the windy and sandy region," International Journal of Coal Science \& Technology, vol. 3, no. 3, pp. 339-348, 2016.

[24] Z. Hu and C. Cao, "Impact of underground coal mining on land ecology and its restoration in windy and sandy region," Journal of Mining Science and Technology, vol. 1, no. 2, pp. 120-130, 2016. 
[25] Y. Sun, J. Zuo, M. Karakus, and J. Wang, "Investigation of movement and damage of integral overburden during shallow coal seam mining," International Journal of Rock Mechanics and Mining Sciences, vol. 117, pp. 63-75, 2019.

[26] J. Ju and J. Xu, "Surface stepped subsidence related to top-coal caving longwall mining of extremely thick coal seam under shallow cover," International Journal of Rock Mechanics and Mining Sciences, vol. 78, pp. 27-35, 2015.

[27] W. Yan, H. Dai, and J. Chen, "Surface crack and sand inrush disaster induced by high-strength mining: example from the Shendong coal field, China," Geosciences Journal, vol. 22, no. 2, pp. 347-357, 2018.

[28] X. L. Yang, G. C. Wen, L. C. Dai, H. T. Sun, and X. L. Li, "Ground subsidence and surface cracks evolution from shallow-buried close-distance multi-seam mining: a case study in Bulianta coal mine," Rock Mechanics and Rock Engineering, vol. 58, no. 2, pp. 2835-3852, 2019.

[29] H. Zhuo, B. T. Qin, Q. L. Shi, and L. Li, "Development law of air leakage fractures in shallow coal seams: a case study in the Shendong coalfield of China," Environmental Earth Sciences, vol. 77, no. 23, pp. 1-11, 2018.

[30] H. Liu, K. Deng, S. Lei, and Z. Bian, "Mechanism of formation of sliding ground fissure in loess hilly areas caused by underground mining," International Journal of Mining Science and Technology, vol. 25, no. 4, pp. 553-558, 2015.

[31] D. Ma, H. Duan, X. Li, Z. Li, Z. Zhou, and T. Li, "Effects of seepage-induced erosion on nonlinear hydraulic properties of broken red sandstones," Tunnelling and Underground Space Technology, vol. 91, p. 102993, 2019.

[32] S. S. Peng, "Topical areas of research needs in ground control a state of the art review on coal mine ground control," International Journal of Mining Science and Technology, vol. 25, no. 1, pp. 1-6, 2015.

[33] X. Y. Yu, P. Wang, and X. L. Li, "Analysis on characteristics of surface subsidence with Han Jia Wan coal mine," Advanced Materials Research, vol. 524-527, pp. 520-524, 2012.

[34] F. Wang, C. Zhang, X. Zhang, and Q. Song, "Overlying strata movement rules and safety mining technology for the shallow depth seam proximity beneath a room mining goaf," International Journal of Mining Science and Technology, vol. 25, no. 1, pp. 139-143, 2015.

[35] Q. H. Huang, "Ground pressure behavior and definition of shallow seam," Chinese Rock Mechanics and Journal, vol. 21, no. 8, pp. 1174-1177, 2002.

[36] M. G. Qian, S. P. Wu, and J. L. Xu, Mine Pressure and Strata Control, pp. 66-90, China University of Mining and Technology Press, Xuzhou, China, 2010.

[37] D. Ma, J. Wang, and Z. Li, "Effect of particle erosion on mining-induced water inrush hazard of karst collapse pillar," Environmental Science and Pollution Research, vol. 26, no. 19, pp. 19719-19728, 2019.

[38] X. Y. Yu, W. B. Guo, B. C. Zhao, and F. L. Wang, "Study on mining subsidence law of coal seam with thick overlying loEss stratum," Coal Science and Technology, vol. 43, no. 7, pp. 6-10, 2015. 